\title{
Habermas y el Neoliberalismo
}

\section{Habermas and the Neoliberalism}

\author{
Ezequiel Ipar \\ Universidad de Buenos Aires, Argentina \\ ezequielipar@conicet.gov.ar
}

Resumen: La teoría de Habermas no se ocupó directamente del neoliberalismo, pero cuando se analiza su obra se percibe que muchos de los conceptos de este gran "marxista académico" han estado dirigidos a estudiar (y combatir) los efectos duraderos de las transformaciones neoliberales. Desde el punto de vista de la crítica al neoliberalismo, su ética del discurso y su teoría de la democracia pueden ser consideradas como un intento por abrir el horizonte normativo desde el cual confrontar contra la apropiación instrumental e individualista de las instituciones de la libertad y la democracia modernas. Esta reconstrucción en el ámbito de una normatividad todavía posible para nuestras sociedades sirve de contrapeso y permite estudiar los modos en los que el neoliberalismo se sobrepone a sus crisis y enfrenta a sus críticos. La curiosa existenciazombi de la política neoliberal, su supervivencia a pesar de sus contrastables efectos destructivos y depredadores, la dificultad para llevar a la práctica verdaderas alternativas democráticas a ese neoliberalismo, todos estos problemas forman parte de la teoría crítica en la que Habermas persevera desde hace más de cuarenta años. En este extenso recorrido, 
Habermas ha dejado el rastro de una verdadera teoría del neoliberalismo contemporáneo que aquí nos proponemos revisar de una manera esquemática y provisoria.

Palabras clave: Jürgen Habermas, teoría crítica, neoliberalismo, democracia, ideología.

Abstract: Habermas's theory did not deal directly with neoliberalism, but when one analyzes his work one can see that many of the concepts of this great "academic Marxist" have been directed at studying (and combating) the lasting effects of neoliberal transformations. From the point of view of the critique of neoliberalism, his ethics of discourse and his theory of democracy can be seen as an attempt to open the normative horizon from which to confront the instrumental and individualistic appropriation of the institutions of modern freedom and democracy. This reconstruction in the realm of a normativity still possible for our societies serves as a counterweight and allows us to study the ways in which neoliberalism overcomes its crises and confronts its critics. The curious zombie existence of neoliberal policy, its survival despite its contrasting destructive and predatory effects, the difficulty of implementing true democratic alternatives to that neoliberalism, all these problems are part of the critical theory in which Habermas has persevered for more than forty years. In this long journey, Habermas has left the trail of a true theory of contemporary neoliberalism that we propose here to review in a schematic and provisional manner.

Keywords: Jürgen Habermas, Critical Theory, Neoliberalism, Democracy, Ideology.

Recibido: I5 de enero de $202 \mathrm{I}$

Aceptado: 23 de enero de $202 \mathrm{I}$ https://dx.doi.org/I O.I 5 I 74/rv.vi 3i27.593 


\section{Introducción}

A pesar de las apariencias, no es fácil definir al neoliberalismo y Amucho menos entender su funcionamiento específico. Sabemos que es un tipo de capitalismo, pero se resiste a la comprensión porque implica combinaciones extrañas de determinaciones económicas, políticas y culturales, promovidas por formas novedosas de coerción y una sorprendente capacidad para generar consensos sociales que operan sobre las creencias de fondo que mantienen la vida social. La teoría de Habermas no se ocupó directamente del neoliberalismo, pero cuando se analiza su obra se percibe que muchos de los conceptos de este gran "marxista académico" han estado dirigidos a estudiar (y combatir) los efectos duraderos de las transformaciones neoliberales. Desde los artículos de coyuntura, que sigue publicando con el ímpetu de un polemista incansable, centrados en el futuro de la Unión Europea bajo las políticas de austeridad neoliberales (Habermas 2009, 2015), hasta su sociología crítica (Habermas 1975, 1987a, 1987b), vemos que siempre se ha interesado por abordar las consecuencias patológicas del tipo de modernización social que promueve el neoliberalismo.

Desde el punto de vista de la crítica al neoliberalismo, su ética del discurso (Habermas, 1994) y su teoría de la democracia (Habermas, 2005) pueden ser consideradas como un intento por abrir el horizonte normativo desde el cual confrontar contra la apropiación instrumental e individualista de las instituciones de la libertad y la democracia modernas. Esta reconstrucción en el ámbito de una normatividad todavía posible para nuestras sociedades sirve de contrapeso y permite estudiar los modos en los que el neoliberalismo se sobrepone a sus crisis y enfrenta a sus críticos. La curiosa existencia-zombi de la política neoliberal, su supervivencia a pesar de sus contrastables efectos destructivos y depredadores, la dificultad para llevar a la práctica verdaderas alternativas democráticas a 
ese neoliberalismo, todos estos problemas forman parte de la teoría crítica en la que Habermas persevera desde hace más de cuarenta años. En este extenso recorrido, Habermas ha dejado el rastro de una verdadera teoría del neoliberalismo contemporáneo que aquí nos proponemos revisar de una manera esquemática y provisoria.

\section{Una verdad muy simple y una coyuntura propicia}

Sabemos que el término neoliberalismo se usa para nombrar muchas cosas, en algunos casos muy diferentes. En primer lugar, usamos el concepto neoliberalismo para referirnos a esa teoría económica que, desde los trabajos de Menger (1884) y el nacimiento de la escuela austríaca (Mises, 1984), se encarga de actualizar la teoría económica clásica a partir de un fuerte giro subjetivista y una teoría del valor que descansa en la teoría de la elección racional. Esta inflexión de la teoría económica, cuya historia ha sido largamente discutida, nace en realidad con una doble cara. Por un lado, estos autores miran hacia el pasado glorioso de los economistas clásicos del siglo XVIII y pretenden defenderlos de sus detractores del siglo xIX, reafirmando en pleno siglo xx una teoría cuasi-naturalista del funcionamiento del sistema económico capitalista. Con la otra cara de sus trabajos miran al presente en crisis, desbordado por los desafíos de la lucha de clases y el demoledor proceso hiper-inflacionario alemán posterior al fin de la primera guerra. Frente a estas emergencias, lo que van a proponer son una serie de medidas monetarias, financieras y fiscales que luego se transformarían en el modelo del paquete ortodoxo en materia de política económica.

De la implicación de la escuela austríaca en los combates de su tiempo y de su idealización de la época clásica del capitalismo, surge el segundo significado al que se refiere habitualmente el término neoliberalismo, esto es, su frondosa doctrina ideológica. Esta ya no viene construida a partir de axiomas y leyes generales sobre el 
funcionamiento de la economía, sino de interpretaciones y exhortaciones que surgen al calor del combate contra la escuela histórica (Schmoller, 1875). En este combate, la doctrina neoliberal lucha contra cualquier orientación del pensamiento social que pretenda negar la verdad última de la antropología del homo oeconomicus o que pretenda sugerir en el plano de la política económica y social un desvío con respecto a los ajustes auto-poiéticos de los intercambios de mercado capitalistas. El nudo de esta doctrina surge del combate contra esos desvíos, que siempre aparecen descriptos con un afán prescriptivo y sancionatorio, confrontando sobre todo con las explicaciones históricas de los procesos económicos y con las reflexiones que pretenden discutir el papel de las instituciones políticas y sociales en el desarrollo del capitalismo. Como para estos autores el desvío más importante de su época con respecto a las reglas del mercado capitalista siempre fue el socialismo, todos los motivos y las representaciones que organizan esta doctrina ideológica neoliberal tienen como sello de fabricación una obsesión antisocialista que no encuentra ningún límite razonable.

Estos discursos teóricos y estas narraciones ideológicas que circulaban en el mundo cultural europeo desde fines del siglo XIX pueden estudiarse desde diferentes prismas. Existe el prisma del economista, que quiere poner a prueba la verdad o la falsedad de las teorías abstractas de los autores de la escuela austríaca. Este abordaje no va más allá de las discusiones específicas en materia de teoría económica y queda asociado a lo sumo a las controversias que despertaron a lo largo de la historia los programas políticos que se suelen deducir de las enseńanzas de la "nueva escuela clásica". También existe el prisma del historiador de las ideas económicas, que sitúa a estos autores y sus descubrimientos en una narración, en un despliegue de la evolución -más o menos polémica- de esta influyente rama de las ciencias sociales, asignándole al neoliberalismo un protagonismo académico hacia comienzos del siglo xx y 
un sorprendente vigor práctico a partir de los años 80 , de la mano de las políticas de Reagan y Thatcher. Finalmente, existe la interrogación del genealogista de las pretensiones de racionalidad, que se interesa por el neoliberalismo como si se tratara de otra estructura discursiva y otra estrategia de poder que consigue erigir socialmente un régimen de verdades universales. Esta perspectiva también se interesa por los modelos de subjetividad que producen performativamente esos discursos que se presentan como racionales.

Reseñamos brevemente estas tres miradas para mostrar de qué modo Habermas sigue un camino distinto. Él aborda al neoliberalismo fundamentalmente con el prisma del sociólogo crítico que, atento a la particularidad de los dilemas de su época, se interesa fundamentalmente por los usos contemporáneos de los textos del neoliberalismo, en un contexto en el que estaba en juego la resolución de los impasses de eso que Habermas llama -con una expresión que no está exenta de ironía- capitalismo "domesticado democráticamente". El neoliberalismo aparece bajo este prisma como una estrategia política, un programa económico y un llamado a refundar las bases culturales de la sociedad que se conectan entre sí a partir de su capacidad para explotar las inconsistencias de la regulación democrática del capitalismo. Esto va de la mano de algo que promueven como una verdad muy simple. Esta simple verdad establece que los intercambios libres realizados en el mercado por individuos auto-interesados son superiores a cualquier otro modo de organización social, tanto en términos de eficiencia, como en términos morales y políticos.

\section{Los limites del Estado de bienestar}

Con el paso del tiempo a nuestro favor, resulta interesante entonces revisar el diagnóstico de los problemas del capitalismo democrático de fines de los años 70, que configuran la coyuntura sobre la que 
se monta el auge del neoliberalismo que todavía estamos viviendo. Habermas llega a este diagnóstico con un arsenal conceptual ya consolidado y con una lectura anticipatoria de las tendencias históricas y las fuerzas sociales en conflicto. La imagen conceptual que usa para describir este proceso es la de un pacto que se rompe, desde diferentes lugares, inclusive por el peso de su propio éxito. Ese pacto era el que había logrado dos grandes objetivos históricos: morigerar o suprimir las crisis recurrentes del capitalismo liberal y conciliar las garantías de rentabilidad para las inversiones de capital con políticas sociales amplias que actuaban amortiguando los costos de la explotación capitalista y dándoles seguridades a los trabajadores a cambio de su lealtad dentro del sistema. Gracias al Estado social el capitalismo había logrado abandonar su tendencia natural a producir recurrentemente crisis económicas, pero lo había hecho al precio de desplazar esas tensiones y esas fuerzas negativas hacia el ámbito de la política y la cultura, que quedaban encargadas de renovar periódicamente el pacto entre capitalistas y trabajadores. Lo que se podía prever a partir de este modelo teórico era que, inclusive frente a la inexistencia de una crisis económica, el pacto social del Estado de bienestar quedara sometido a importantes presiones y crisis de legitimidad, debido a la sobrecarga que adquiría el gobierno del Estado y a su incapacidad para resolver los problemas estructurales que el capitalismo le impone al conjunto de la sociedad (Habermas, 1975).

Para describir con precisión el contexto de aparición del neoliberalismo como voluntad de poder Habermas va a tirar de la punta del hilo que había quedado establecida en Problemas de legitimación en el capitalismo tardio. A diferencia de los economistas heterodoxos, que describen la crisis del modelo del Estado de bienestar a partir de los problemas inflacionarios o de los acontecimientos imprevistos vinculados a la crisis del petróleo, el análisis de $\mathrm{Ha}$ bermas se centra en las contingencias políticas que atravesaba el 
pacto del capitalismo democrático (Habermas, 1983c). Lo más importante de este análisis lo encontramos en la atención que le presta a los costos de ese modelo de capitalismo, en la sensibilidad conceptual que conserva para seguir escuchando el sufrimiento que quedaba silenciado bajo la legitimación que proveía el Estado capitalista reformado:

Desde la perspectiva subjetiva del ciudadano del sistema económico, el compromiso del Estado social consiste en que se gane lo suficiente y se obtenga la suficiente seguridad social para poder reconciliarnos con las tensiones de un trabajo más o menos alienado, con las frustraciones de una función más o menos neutralizada como ciudadano sin más, con las paradojas del consumo de masas, por ejemplo, durante las vacaciones anuales explotados por los circuitos turísticos; con el fin de reconciliarse con la miseria de una relación clientelista con las burocracias. Este compromiso aparece ahora amenazado por dos lados. Evidentemente, la política económica neokeynesiana ya no alcanza a asegurar el crecimiento que es necesario para garantizar el pleno empleo y detener los conflictos causados por la redistribución. Los signos más claros de este compromiso que, por así decirlo, se ha quebrado, son reducciones de los ingresos reales de la masa de la población, paro y pobreza para una minoría creciente, quiebras de empresas y, al mismo tiempo, mejoras en las condiciones de inversión y también tasas de beneficios creciente para una minoría muy reducida (Habermas, 1983b: 49).

Dos cargas del compromiso del Estado de bienestar destacadas por Habermas en este análisis aparecerán luego como blancos estratégicos de la doctrina neoliberal, que exalta naturalmente el papel del sujeto individual en cualquier contexto social. En primer lugar, la relación clientelista con el sub-sistema administrativo del Estado 
que se encarga de aplicar las políticas de seguridad social. Esta relación, necesaria para organizar sistemas de redistribución económica en sociedades complejas, va borrando en su propio desarrollo histórico la dimensión ética y la vitalidad política de las luchas que fueron necesarias para imponer criterios básicos de justicia social al interior de una sociedad capitalista. Cuando ciertos niveles de igualdad se alcanzan en sociedades que se siguen reproduciendo a partir de la desigualdad, los mecanismos administrativos a los que recurre el Estado para garantizar esa igualación en el acceso a bienes económicos comienzan a dejar de despertar el interés de los ciudadanos y son percibidos como una captura burocrática de sus demandas y sus auténticos deseos de emancipación. Como el bienestar económico que garantizan las políticas sociales no realiza todas las aspiraciones de emancipación social que están presentes y son estimuladas por la propia democratización del capitalismo, quedan abiertos una serie de desafíos y posibilidades históricas que el aparato administrativo del Estado no puede atender con ninguna de sus caras, ni la cara amable de la protección social, ni la cara fría del Estado planificador.

En segundo lugar, Habermas pone la mirada sobre un tipo de trabajo explotado y alienado, que permanece idéntico en el contexto de un mercado que ofrece, en términos históricos, mejores condiciones salariales. Esta alienación, vivida subjetivamente en la fábrica industrial, se extendía también al tiempo libre y al espacio público. Con este diagnóstico Habermas seguía atento al concepto de industria cultural de Adorno y Horkheimer. No habría que olvidar que, en principio, lo que en realidad le ofrece al sujeto el modelo del capitalismo regulado es una salida compensatoria: seguridades económicas a cambio de la reproducción de un sacrificio y una pérdida de autonomía que este debe aceptar sin romper las condiciones del pacto. A su vez, como este proceso va acompańado de una reconversión tecnológica que aumenta la productividad del 
trabajo, con ella se intensifica la experiencia del carácter injustificado de la ética profesional sacrificial, cuya persistencia irreflexiva depende para los trabajadores de una responsabilidad del Estado social.

Frente a esta doble carga del capitalismo regulado, resultaba razonable pensar que las fantasías neoliberales del individuo soberano podían ser usadas ideológicamente para capturar este doble malestar: por un lado, el malestar que provoca la tutela reguladora del Estado social, con todos sus tentáculos burocráticos intentando dar respuesta a las demandas de justicia social; por otro lado, la experiencia rutinaria de estar anclado en un puesto de trabajo que no permite la auto-realización del sujeto y que responde más a las expectativas sistémicas de la máquina social que a los deseos del individuo que trabaja.

\section{La emancipación no es administrable}

Este modelo de regulación del capitalismo no solo resulta costoso en términos subjetivos, sino que también tiene serias dificultades para comunicarse con la creatividad colectiva y las nuevas necesidades de participación social en los asuntos comunes. Habermas detallaba esta situación con mucha precisión, siguiendo una especie de dialéctica de los movimientos sociales de su época:

Me refiero a los problemas que han puesto de relieve los ecologistas, las culturas alternativas, los nuevos movimientos sociales; esto es, los costes de la modernización capitalista y el fracaso de una política de defensa estratégicamente calculada, pero que no se apoya en una voluntad general. Hay dos aspectos que resultan las amenazas más absurdas y los peligros más endiablados a medida que ambos crecen, crecen y crecen: tanto las fuerzas productivas y la riqueza abstracta como las fuerzas destructivas y los arsenales. 
Todo esto nos resulta cada vez más absurdo a medida que nuestras capacidades de experimentación, nuestra fantasía, nuestras posibilidades de imaginación, nuestra consciencia de la responsabilidad, nuestro entendimiento, nuestros sentimientos, por ejemplo, la gama que va del amor al odio, renquean detrás de las posibilidades técnicas de dominación y destrucción de la naturaleza y detrás de la complejidad de los entramados sociales. Cuando se trata de la sustancia de los fundamentos, ya sea en la naturaleza, en el medio urbano, en el medio familiar, en la escuela, entonces se dan manifestaciones de carencias y de privaciones en torno a las cuales se constituyen nuevos frentes de conflictos (Habermas, 1983b: 49-50).

Toda cosificación es un olvido, había sostenido Adorno. Y lo que a Habermas le interesa es transformar esa intuición teórica en una de las claves para la sociología crítica de la modernidad. De esa manera, una nueva constelación de problemas surgen cuando de lo que se trata es de lidiar con la experiencia del absurdo al que tiende la modernización social capitalista, que estimula incesantemente el crecimiento, olvidando para qué se crece y a qué costo en términos ecológicos, de oportunidades de vida colectiva malogradas, de represiones subjetivas y de incremento de nuevas fuerzas de destrucción y violencia. Evidentemente, lo nuevo no era este hallazgo teórico sobre la dialéctica de la modernización, que les pertenece a Marx y Weber en diferentes aspectos, sino el nivel de reflexividad sobre el mismo que parecía haber hecho posible el proyecto socialdemócrata de regulación del capitalismo. Ese proyecto había vuelto experimentable en amplias capas de la sociedad ese absurdo de la acumulación económica que se transforma en un fin en sí mismo. Junto con esa experiencia de lo absurdo del capitalismo parecía haber surgido también la oportunidad de la crítica y de una propuesta de transformación. Finalmente, se había logrado 
desenmascarar en el plano del debate público la relación que existe entre el crecimiento abstracto de la riqueza y la intensificación de nuevas fuerzas destructivas. Sin embargo, en el momento más alto de la regulación socialdemócrata del capitalismo, se comprobó que el compromiso con el crecimiento económico no permitía traducir políticamente esa reflexividad crítica. Esto implicaba que la socialización de la crítica no encontraba el camino para realizarse a través del Estado en procesos efectivos de transformación social. El mismo bloqueo encontraban la experimentación cultural y la efervescencia del modernismo artístico, cuyos valores asociados a la imaginación, la innovación y la creatividad no tenían ninguna resonancia significativa en la mesa neo-corporativa del capitalismo socialdemócrata.

Así se abría una nueva puerta de entrada para la doctrina neoliberal, que podía volver a ofrecer al mercado como modelo excitante de una sociedad competitiva e innovadora.

\section{La dialéctica de la desigualdad}

El tercer aspecto del diagnóstico sobre la coyuntura propicia para el neoliberalismo muestra una gran capacidad de anticipación. Lo que ahora le interesa destacar a Habermas son los riesgos y los efectos ideológicos de un nuevo tipo de crecimiento económico, que iba a generar necesariamente una nueva estructura de clases, con altos niveles de pobreza y exclusión social. Este crecimiento acelerado, que busca maximizar las garantías para la oferta de inversiones productivas, iba a terminar normalizando y volviendo aceptables altos niveles de desigualdad y exclusión social:

Una política económica orientada a la oferta en las condiciones actuales, también ha de resignarse a la existencia de un paro muy numeroso a largo plazo. Ello podría conducir a una nueva seg- 
mentación de la sociedad en ins y outs, en la que los ins se componen de minorías sociales privilegiadas que constituyen una mayoría frente a los expulsados del sistema productivo. La mentalidad de una mayoría con conciencia de clase media que se prepara para una separación duradera frente a una minoría muy subprivilegiada es algo que, en algún momento, solo podrá describirse mediante el vocabulario del darwinismo social, un vocabulario que hoy ha revivido sorprendentemente en las conversaciones sobre las élites, en la preparación para la concurrencia y para la imposición (Habermas, 1983: 51).

Claramente esta predicción de comienzos de los 80 se volvió una verdad global según estudios como los de Piketty (2015) y Milanovic (2016). Sabemos que esa diferencia es la que promueven las políticas económicas neoliberales, que reducen las regulaciones al capital y estimulan una competencia global por las inversiones productivas que solo acrecienta la división entre insiders y outsiders. Pero lo que resultaba inimaginable en ese momento era que la gramática darwinista y la necesidad de justificación de nuevos niveles de las desigualdades sociales pudieran tener tanto éxito. A partir de allí, pudieron inscribirse a través de diferentes narraciones en una ciudadanía que hasta hacía muy poco se había acostumbrado a demandarle al Estado mecanismos para hacer efectivos los derechos sociales. Con esa transformación, la fría ideología liberal volvía a cumplir el mismo papel que había intentado desempeñar durante el siglo XIX.

De la mano de esta necesidad de volver a justificar nuevas diferencias y exclusiones sociales, se incorpora al contexto de aparición del neoliberalismo un tipo particular de supervivencia del tradicionalismo cultural. Este tradicionalismo post-secular se da al interior de sociedades supuestamente constituidas a partir de identidades post-nacionales y post-convencionales: 
El segundo ingrediente es el constituido por un tradicionalismo que en la política cultural, educativa y familiar (si bien no en la política de medios de comunicación que afecta de modo inmediato a los intereses económicos) descansa sobre las virtudes secundarias, los pasados gloriosos, el common sense, la conciencia histórica ininterrumpida y la religiosidad convencional, esto es en la naturalidad: nada de reflexión y sólidos valores. Por el contrario, la modernidad cultural se considera subversiva. La "renovación espiritual y moral" implica un retroceso a una época anterior al siglo Xvin del que se espera una regeneración maravillosa de las evidencias mismas, una almohadilla tradicional que da buena cuenta de las cargas y en la que siempre fracasan las orientaciones y los controles burocráticos (Habermas, 1983: 51-52).

Aquí aparece otro de los trazos persistentes de la ideología neoliberal: su multifacética pulsión anti-intelectual. Visto desde la consciencia post-tradicional que le daba forma al "capitalismo domesticado democráticamente" de la post-guerra, este rasgo también resultaba sorprendente. Inclusive por su afinidad con las regulaciones tecnocráticas, esta fusión del neoliberalismo con la reemergencia de un pasado cultural reprimido, montado sobre una ética fuertemente particularista y tradicionalista, no era fácil de diagnosticar en sus comienzos.

\section{Viejos, nuevos y jóvenes conservadores: la resolución política del neoliberalismo.}

Si para definir el concepto de neoliberalismo tenemos que partir con Habermas de una clara exposición de los dilemas del "capitalismo domesticado democráticamente", el siguiente paso consiste en esclarecer el mecanismo que le va a permitir ser eficaz sobre 
esa coyuntura, es decir, el mecanismo que le permite transformar radicalmente la regulación de la economía, promover nuevas formas de apaciguamiento y control de los conflictos sociales y conseguir una legitimidad duradera basada en combinaciones originales de viejas tramas culturales, que se funden con nuevas formas de neutralizar las energías emancipadoras de la cultura. Este último aspecto relativo a las formas de legitimación del neoliberalismo va a ser el foco de nuestra atención. Aun cuando nos detengamos en coordenadas muy generales, estas sirven para esclarecer sorprendentes invariantes de eso que con justicia teórica podemos llamar la lógica cultural del neoliberalismo.

Uno de los aspectos fundamentales que le interesan advertir a Habermas sobre el nacimiento de esta lógica cultural neoliberal es la extraña síntesis que puede ofrecer para darle respuesta a los impasses del modelo socialdemócrata de capitalismo. En el largo recorrido de sus análisis sobre esta nueva formación cultural, siempre estuvo clara la idea de que en la base de lo que se trataba era del conservadurismo. Su complejidad provenía de las variaciones de conservadurismo que lograba combinar. Como si se tratara de sinónimos, para Habermas la lógica cultural de esta transformación neoliberal incluía la acción concertada de diferentes tipos de conservadurismo. Para reconstruirla vamos a usar la provocadora tipología que propuso Habermas (1983a) en su clásica intervención en el debate modernidad/postmodernidad, pero la vamos a desplazar del trasfondo filosófico y de la discusión con los grandes nombres de la controversia original. Nos vamos a concentrar en la construcción de una tipología de las orientaciones político-ideológicas que sirven para ensamblar la lógica general de la cultural neoliberal. Hay varios elementos que vale la pena rescatar en estas tempranas intuiciones teóricas, que siguen teniendo una enorme actualidad.

Del neo-conservadurismo la lógica cultural neoliberal extrae sobre todo un imperativo práctico, que va a recubrir a la propia 
fuerza que ejerce la dominación capitalista dentro del sistema económico. Este imperativo exige proteger e inmunizar al sistema económico de cualquier influencia o distorsión externa. Es el ideal de la teoría de los sistemas auto-regulados, que en este caso necesitan repeler cualquier influencia por parte de experiencias, deseos y discursos sociales que pudieran articular demandas no generadas dentro de las reglas del propio sistema. En términos teóricos, el neo-conservadurismo instituye la inmunidad del sistema económico frente al mundo de la vida de los ciudadanos, de modo tal que se neutralizan las pretensiones de validez de cualquier demanda o crítica orientada a obtener otros resultados distributivos u otras formas de organización del sistema económico. En su implicancia ideológica, el imperativo neoconservador busca desacreditar el poder comunicativo de los ciudadanos cuando este pretende ejercer una influencia sobre la economía. Este propósito se logra a través de un discurso admonitorio que advierte que cualquier límite a la acumulación capitalista va a producir necesariamente un resultado negativo en el largo plazo para la sociedad.

Como sabemos, este mandamiento neoliberal se repite con una sorprendente rigidez desde la época de la revolución neo-conservadora de Reagan y Thatcher. A modo de ejemplo, que cualquier lector podría multiplicar por su cuenta, voy a citar a un candidato a presidente argentino de centro derecha, que enuncia este imperativo -apenas implícito bajo la forma de una enunciación disyuntiva- con una notable sobriedad: "Cuanto más reglas menos inversiones. Cuanto más intervenciones menos productividad. Cuanta más creatividad [presión] fiscal más desvíos”. ${ }^{1}$

Esta avanzada neoconservadora implicaba por lo tanto el abandono del dualismo que había caracterizado al capitalismo re-

${ }^{1}$ Carta de Roberto Lavagna: Llegó la hora, no más excusas. Publicada en sus redes sociales: https://twitter.com/RLavagna (26/xiI/2020). 
gulado, que podía llegar a una solución de compromiso con las demandas democráticas, mientras conservaba los estímulos y las garantías para la reproducción de la acumulación capitalista. Su ideal sistémico establece un capitalismo irreformable desde afuera, cuya legitimación depende de discursos que oscilan entre la teoría económica (más o menos fundamentada), las prescripciones farmacológicas en materia de política y una doctrina que exalta los valores de un hiper-individualismo en las masas.

$\mathrm{Al}$ poner bajo la lupa a esta rama neoconservadora de la lógica cultural neoliberal encontramos una determinación que es esencialmente negativa, dado que lo que indisimuladamente se busca es anular, rechazar, desarmar o bloquear el poder que pueden constituir los ciudadanos en el mundo de la vida. En los términos de la Teoría de la Acción Comunicativa se trata, por un lado, de un desanclaje del sistema económico con respecto al mundo de la vida (Habermas, 1987b: 366 y ss.), que va a implicar una desorganización de la sociedad civil (Offe, 1985) y un menoscabo en la subjetividad. Cuando se desprende de sus compromisos normativos, este sistema económico le quita recursos y garantías al desarrollo de la personalidad, y suprime los órdenes legítimos que coordinaban diferentes interacciones valiosas para la sociedad. Aquí el neoliberalismo avanza rompiendo la mesa de negociación de intereses contrapuestos y reduciendo al mínimo posible la influencia de la opinión pública en los asuntos económicos. Lo que promueve es un sistema económico transformado, que necesita menos anclajes en la sociedad y los sujetos para garantizar sus mecanismos autoproductivos, debilitando de este modo dos de los recursos más frágiles de la modernidad: solidaridad y sentido.

En la polémica que Habermas sostuvo con Foucault (Habermas, 2008), también habría que incluir esta discrepancia sobre los efectos y la lógica general de los discursos neoliberales. Foucault había menospreciado, de un modo apresurado y siguiendo 
solo "el orden del discurso", la dimensión negativa de la lógica del poder neoliberal, fundamentalmente porque no encuentra en la destrucción de los mecanismos de regulación del Estado social ningún material que le resulte relevante. Contra ese dogmatismo del carácter siempre afirmativo del poder, la teoría de Habermas permite pensar de qué modo el neoliberalismo se institucionaliza desinstitucionalizando potencialidades expresivas y comunicativas de la ciudadanía, silenciando las fricciones de la acumulación capitalista. El neoliberalismo es en este sentido un corte, una ruptura de los lazos que trasladaban -con todas las distorsiones del caso- la voz de los ciudadanos hacia los mecanismos que dirigen el sistema económico.

Con respecto a los jóvenes conservadores, su aporte específico dentro de la lógica cultural neoliberal consiste, sin dudas, en la exaltación de la imaginación irreverente, la innovación tecnológica y la creatividad individual, todo eso que parecía estar ausente del modelo socialdemócrata (o keynesiano) de regulación social. Es fácil encontrar en los jóvenes neoliberales que habitan la cúspide del capitalismo digital muchas coincidencias con este trazo de la cultura posmoderna que consiste en la supresión o la oposición al ámbito de lo normativo, sobre todo de la normatividad moral y política que observan como un obstáculo anacrónico que limita sus fuerzas creativas y su voluntad de poder. Lo que los jóvenes neoliberales toman de los jóvenes conservadores es el espíritu de rebeldía contra las formas alienantes de la modernidad económica y política. Son promotores de un tipo de desalienación del sujeto que lucha contra todo paradigma cultural universalista, que iguala y homogeneiza lo que debe permanecer diferente.

Para llevar hasta sus últimas consecuencias estas críticas, los jóvenes neoliberales también invocan el espíritu del modernismo estético, el disfrute de una vida que juega todo el tiempo con el azar y las experiencias subjetivas más disruptivas. Pero su singula- 
ridad consiste en que invocan estas fuerzas rebeldes para reintroducirlas en el mundo del trabajo, como si fuera viable emanciparse del proyecto de vida que emana del trabajo alienado de la gran industria a través de excitantes y extenuantes jornadas de trabajo en los laboratorios creativos del capitalismo digital. En este aspecto, el neoliberalismo también se nutre de la crítica artística a las obligaciones sociales clásicas de la modernidad, pero lo hace de una manera paradójica, reencauzando hacia el propio sistema económico esas fuerzas críticas, diluyéndolas en un reencantamiento del viejo mundo laboral del capitalismo, desbordado ahora por las imágenes ideológicas de "imaginación, innovación y creatividad". Habría que pensar a esta operación siguiendo a Benjamin como una estetización de la explotación capitalista, en la que los aumentos de productividad y el crecimiento irreflexivo de la riqueza abstracta aparecen estimulados por un vitalismo tecnológico saturado de artificios estéticos.

Frente a un problema semejante de la cultura moderna, Adorno utilizó un concepto que resultaría útil retomar en nuestro contexto particular, el concepto de pseudo-actividad (Adorno, 1997: 794 y ss.). Este concepto le servía para interrogar la capacidad que tiene el capitalismo para estimular en los sujetos la sensación de estar inmersos en un mundo lleno de acciones incesantes. Ese mundo en constante movimiento le comunica al sujeto la falsa representación de que él está en el centro de la actividad, de que finalmente ese vértigo de actividad incesante depende de fuerzas que le pertenecen. ${ }^{2}$ Si trazamos una analogía entre el concepto de Adorno y los análisis teóricos de Habermas, podemos hacer surgir el concepto de pseudo-subjetivación, para dar cuenta de esta determinación de la cultura neoliberal en la que se imitan los motivos de la subje-

${ }^{2}$ Para Adorno, esta representación ilusoria de la pseudo-actividad creaba en los sujetos una auténtica fábrica de la decepción y el resentimiento. 
tivación artística al interior de un agobiante mecanismo de reclutamiento de la nueva fuerza de trabajo. La pseudo-subjetivación depende de la promesa de una desalienación de la individualidad con respecto al mundo del trabajo industrial y la servidumbre del Estado, pero que se realiza disciplinadamente dentro de los límites y las reglas del capitalismo desorganizado.

Hacer de la propia vida una obra de arte es algo que comparten Jeff Bezos o Mark Zuckerberg con los modernistas del siglo pasado. Pero esta aventura singular, que abraza al individuo que toma riesgos y se pone siempre entre los primeros para experimentar e innovar, exige hacer a un lado la reflexión moral, desentenderse de los conflictos del mundo del trabajo, de la exclusión, de la precariedad y en general de las viejas cuestiones que la clase trabajadora había tratado con el horizonte normativo de la justicia social. Este es el reverso del capitalismo creativo, que los jóvenes neoliberales aceptan sin culpas. El modelo subjetivo no deja de ser un modelo compensatorio, solo que ahora cambian los términos y es el endurecimiento frente al sufrimiento de los semejantes el que pasa a ser compensado por la experiencia extática del mundo de la innovación y la creatividad sin límites. Lo que Habermas intentó mostrar desde que comenzó con esta crítica a los “jóvenes conservadores” era que esta separación de los valores del modernismo estético con respecto a una modernidad política y moral que podía ser revisada, iba a conducir a una fusión de esa gestualidad rebelde con la lógica del capital. Y eso es lo que, casi 40 años después, observamos en todo su esplendor en la cultura de los jóvenes neoliberales, que admiran el más allá de los viajes a las estrellas mientras se olvidan de cualquier reflexión moral sobre sí mismos.

A esta combinación los viejos conservadores le aportan un tipo de rechazo más decidido frente a la reflexión crítica y una activa promoción de valores sociales arcaicos. Como los nuevos conservadores imponen una racionalidad que provoca des-anclajes del 
sistema económico con respecto al mundo de la vida y los jóvenes conservadores se caracterizan por la evasión frente a los dilemas morales, son los viejos conservadores los que cubren ese vacío normativo y esa ausencia de sentido. Trabajando en la retaguardia de esta construcción ideológica, apuntan a regenerar los viejos lazos sociales que derribó el proceso de modernización cultural. De allí que la comprensión del mundo social que le aportan al neoliberalismo aluda insistentemente a la idea de una gran desposesión y una pérdida incalculable de los valores que suponen que hicieron grande a sus sociedades en el pasado y que deberían volver a recuperar su fuerza vinculante para garantizar el único futuro dentro del capitalismo con el que pueden reconciliarse.

El neoliberalismo encuentra de este modo una alianza estratégica con un tipo de identidades tradicionales que no debería sorprender, porque el prefijo "neo" perfectamente puede implicar la novedad de lo más antiguo, de lo que había quedado en un pasado remoto, sobre todo cuando se trata de reforzar los valores de la propiedad, las jerarquías sociales y el orden domestico (Brown, 2019: 89 y ss.). A su vez, la "regeneración cultural" que se remonta al universo de valores y representaciones del mundo "anteriores al siglo XVIII" preparan el componente autoritario del neoliberalismo, que podemos observar con claridad en los movimientos políticos que luchan contra los derechos de las mujeres, de la diversidad sexual, de las clases sociales desfavorecidas o los que se oponen a las políticas anti-racistas. En todos estos casos se esgrimen efectivamente valores naturalizados que pretenden defender el valor de la vida de los embriones, de las identidades sexuales consagradas por la religión y así con el resto de sus contraposiciones. Lo "natural" aludido por este tipo de conservadurismo depende de su rechazo a la ampliación del principio igualitario de la normatividad moderna. Ese es el material cultural con el que los viejos conservadores no pueden reconciliarse y por eso proponen un proceso histórico que 
debería desarrollarse invirtiendo la secuencia de los derechos de Marshall: luchar ferozmente contra los derechos sociales que consideran un despilfarro, buscar limitar los derechos de participación política que consideran peligrosos y tolerar los derechos civiles básicos exclusivamente allí donde no pongan en riesgo la propiedad y la familia. El principio práctico que guía a esta orientación de la cultura neoliberal dice sin culpas: no somos, ni podemos, ni debemos ser iguales.

\section{Para concluir: neoliberalismo o democracia.}

Cuando reconstruimos los elementos de la teoría de Habermas sobre el neoliberalismo vemos trabajando la potencialidad de una sociología crítica, inspirada por una densa arquitectura conceptual y una preocupación aguda por el presente político. Su punto teórico más consistente lo provee sin dudas la ambición de su programa sociológico, que todavía quiere ofrecer conceptos que permitan dar cuenta de la relación entre economía, política y cultura en sociedades capitalistas complejas, atravesadas por una superposición de crisis históricas que son difíciles de calibrar dentro de una misma representación de la sociedad. En el estudio del neoliberalismo esta ambición teórica implica analizar el devenir de un sistema económico capitalista que busca perseverantemente zafarse de su domesticación democrática y diluir las tradiciones culturales modernas en una versión estrecha de la racionalidad. Dentro de este movimiento histórico, los discursos ideológicos neoliberales cumplen papeles muy precisos: resignifican los costos del capitalismo para los sujetos, socavan la legitimidad de los proyectos transformadores encarnados en el Estado de bienestar, monopolizan las imágenes y las proyecciones racionales que abren el horizonte del futuro, vuelven aceptables formas de desigualdad social creciente y justifican un modelo de sociedad de incluidos y excluidos. 
Las tres posiciones que Habermas diagnosticó tempranamente siguen configurando la lógica cultural del neoliberalismo a partir de combinaciones que son particulares, por lo que siempre debemos estudiar los casos empíricos para entender las variaciones contemporáneas de este tipo de capitalismo. En muchas oportunidades estas posiciones se renuevan a partir de plexos culturales diferentes, se intensifican en sus luchas o asumen nuevos papeles. Pero podemos reconstruir un movimiento general que sirve para pensar la situación actual a escala global, que es la auténtica escala del neoliberalismo. Sin dudas, el neo-conservadurismo es el motor de esta experiencia histórica, porque es la posición que reorienta todas las instituciones jurídicas y políticas, poniéndolas al servicio de la inmunización de un sistema de explotación económica acelerado, que busca neutralizar cualquier interferencia democrática crucial. Esta inmunización bloquea también cualquier posibilidad de realizar aprendizajes históricos por parte de las sociedades, porque su modelo de integración solo conecta mercados de consumo con procesos productivos globalizados a través de la mediación de un mercado financiero inexpugnable. Lo hemos visto en la reciente crisis financiera global del año 2008: lo único que se termina imponiendo es la recomposición de los circuitos del dinero. Confrontado con la trama política y cultural -que ha quedado en pie- del "capitalismo domesticado democráticamente", el neoconservadurismo solo avanza promoviendo nuevos des-anclajes entre ese sistema económico y el mundo de la vida de ciudadanos que se sienten cada vez más desorientados e impotentes.

Este concepto de des-anclaje del sistema requeriría un análisis más extenso, pero sabemos que implica no solo una desconexión con respecto a los valores y las normas legítimas de una sociedad, sino también una pérdida de fuerza motivacional en los sujetos. Para decirlo de otra forma, la programación neo-conservadora del neoliberalismo no puede generar -mucho menos hoy, luego de la 
crisis- convicciones profundas y ámbitos de intereses compartidos que vuelvan a inscribir en tanto sujetos a los miembros de ese sistema social. Al menos esto es lo que creía Habermas con respecto al poder universal pero limitado del dinero como medio de intercambio social. En su teoría, inclusive allí donde logra colonizar esferas de la vida social construidas a través de la comunicación intersubjetiva, el dinero siempre encuentra el límite infranqueable de la falta de sentido, porque confronta directamente al sujeto con el absurdo de la acumulación de capital como un fin en sí mismo. En este punto empiezan las preguntas que nos deja abiertas nuestro presente ideológico, porque evidentemente las otras dos posiciones neoliberales cumplen un papel crucial frente a esta falla en la programación del sistema. Pero antes de pasar a eso, quisiera señalar una duda con respecto al poder de vínculo del dinero. Tal vez algo de la crítica que conocemos desde Marx hasta Habermas sobre los efectos sociales de la abstracción del dinero haya cambiado con el dinero digital y las tecnologías personalizadas que tiene asociadas. Surge allí una posibilidad que para el sistema neoliberal no sería trivial. Formulada como preguntas dirían así: ¿’podrá el algoritmo financiero personalizado cumplir el papel que no pudo cumplir hasta aquí el dinero, transformándose en el organizador autónomo de todos los intercambios sociales, prescindiendo de la política, la cultura y la subjetividad?, ¿hasta dónde puede llegar la colonización de otras esferas de la vida sin subvertir de raíz su naturaleza socio-cultural?

Dejando a un lado el posible retorno de controles autoritarios, las otras alternativas que se dibujan en el horizonte para el neoliberalismo son los anclajes que le proveen la cultura de los jóvenes neoliberales y las orientaciones político-ideológicas de los viejos conservadores. De la cultura de los jóvenes conservadores depende la posibilidad de seguir encendiendo en los sujetos la ilusión de la autonomía, la creatividad y la innovación, a pesar de que lo hagan 
sobre un futuro imposible, en el que conviven armónicamente la explotación capitalista y la pseudo-subjetivación. En esta situación, los viejos conservadores construyen la retaguardia móvil, que siempre puede volver a ocupar un papel protagónico resacralizando la libertad de los propietarios y agitando el látigo de los valores tradicionales que habían sido erosionados por la modernidad política y cultural. Su cruzada anti-igualitaria no para de crecer.

Cuando se esclarece el contenido de este plexo político-cultural se ponen de manifiesto de un modo más nítido los elementos anti-democráticos del neoliberalismo. Finalmente, lo que tienen en común la neutralización de la política que llevan a cabo los neo-conservadores, la indiferencia frente a los asuntos normativos que promueven los jóvenes neoliberales y la violencia de los valores anti-igualitarios de los viejos conservadores, es su rechazo de las prácticas y las instituciones de la democracia. Esta es la dialéctica que siempre le interesó demostrar a Habermas, ya que en las tres posiciones que conforman su lógica cultural lo que se tiende a suprimir es la formación libre de una voluntad política con capacidad de incidir y la posibilidad de que la experimentación y la innovación social tengan un fundamento democrático. Para enfrentar esta deriva acelerada, el lado crítico y la indagación normativa de su teoría han intentado -con diferente fortuna- mostrarnos los trazos generales de otro proyecto de sociedad, en el que la democracia no es solo un contrapeso de un sistema económico omnipotente, sino una nueva forma de vida cuyos posibilidades históricas todavía no han sido realizadas. 


\section{Bibliografía}

Adorno, Theodor,1997, Kritische Modelle III, en Gesammelte Schriften X, Suhrkamp, Frankfurt am Main.

Brown, Wendy, 2019, In the Ruins of Neoliberalism. The rise of antidemocratic politics in the west, Columbia, Nueva York.

Habermas, Jürgen, 1975, Problemas de legitimación en el capitalismo tardío, Amorrortu, Buenos Aires.

, 1983a, "La modernidad: un proyecto inacabado", en Ensayos Políticos, Península, Barcelona.

, 1983b, "Después del camino: Política conservadora, trabajo, socialismo y utopía hoy", en Ensayos Políticos, Península, Barcelona.

, 1983c, "La nueva oscuridad de la política social y el agotamiento de las energías utópicas", en Ensayos Políticos, Península, Barcelona.

, 1987a, Teoría de la acción comunicativa I, Taurus, Madrid. , 1987b, Teoría de la acción comunicativa II, Taurus, Madrid.

, 1990, "Acciones, actos de habla, interacciones lingüísticamente mediadas y mundo de la vida", en Pensamiento Postmetafisico, Taurus, Madrid.

, 1991, "La revolución recuperadora", en La necesidad de revisión de la izquierda, Tecnos, Madrid.

, 1994, Conciencia moral y acción comunicativa, Planeta, Barcelona.

, 2005, Facticidad y validez, Trotta, Madrid.

,2008, "Aporías de la teoría del poder", en El discurso filosófico de la modernidad, Katz, Buenos Aires. 
,2009, Europe The Faltering Project, Polity Press, Cambridge. , 2015, The Lure of Technocracy, Polity Press, Cambridge.

Ipar, Ezequiel, 2018, "Neoliberalismo y neoautoritarismo", Politica y Sociedad, t. 3, núm. 55, pp. 825-849.

Menger, Carl, 1884, Irrthümer des Historismus in der deutschen $\mathrm{Na-}$ tionalökonomie, Höler, Viena.

Milanovic, Branko, 2016, Global inequality: A new approach for the age of globalization, Harvard University Press, Cambridge.

Mises, Ludwing von, 1984, The historical setting of the Austrian school of economics, Arlington House, Nueva York.

Offe, Claus, 1985, Disorganized Capitalism: Contemporary Transformations of Work and Politics, MIT Press, Cambridge.

Piketty, Thomas, 2015, El capital en el siglo XXI, Fondo de Cultura Económica, Buenos Aires.

Schmoller, Gustav von, 1875, Die soziale frage: Klassenbildung, Arbeiterfrage, Klassenkampf, Duncker \& Humblot, Berlín. 